\title{
UTOPIAS PENITENCIÁRIAS PROJETOS JURÍDICOS E REALIDADE CARCERÁRIA NO BRASIL
}

\author{
Regina Célia Pedroso*
}

\begin{abstract}
RESUMO: Este texto pretende inserir na discussão historiográfica sobre violência, uma temática pouco explorada a nível histórico: o sistema penitenciário. Para isso escolhi uma questão que considero polêmica: as utopias penitenciárias, projetos idealizados por juristas nos séculos XIX e XX com o intuito de sanear o problema da superlotação carcerária. Destaco o projeto da Cidade Penitenciária do Rio de Janeiro, o selo penitenciário e as Colônias de Defesa Social, nos quais pretendia-se dar ao preso condições ideais de vida no interior do cárcere. Ou então, soluções paliativas, como a utilização de lazaretos ou abrigos para tuberculosos. Projetos e soluções que, com o transcorrer do tempo, tornaram-se inviáveis.
\end{abstract}

ABSTRACT: This paper pretends to contribute to the historiographical debate on violence, stressing a theme little explored on the historical level: the penitentiary system. Consequently, I selected an argument that I consider to be polemic: the utopias of the penitentiary system - projects idealized by jurists in the XIX and XX centuries, intending to solve the problem of overcrowded prisons. I highlight the following projects: "Cidade Penitenciária do Rio de Janeiro", the "Selo Penitenciário" and the "Colônias de Defesa Social", whose intents were to give the prisoner ideal life conditions inside the prison. Or, at least, to provide palliative solutions, as the utilization of Pest-houses and asylums for the tuberculous prisioners. Projects and solutions that, in process of time, became impracticable.

PALAVRAS-CHAVES: Utopia, Sistema Penitenciário, condições carcerárias, idéias jurídicas, violência.

KEYWORDS: Utopia, Penitentiary System, Jail conditions, Juridical ideas, violence.

A História do Sistema Penitenciário brasileiro foi marcada por episódios que revelam e apontam para o descaso com relação às políticas públicas na

* Doutoranda em História Social pela USP e Pesquisadora no Instituto Latino Americano das Nações Unidas para a Prevenção do Crime e Tratamento do Delinqüente - ILANUD área penal, como também para a edificação de modelos que se tornaram inviáveis quando de sua aplicação.

A prisão, símbolo do direito de punição do Estado, teve, quando de sua implantação no Brasil, 
utilização variada: foi alojamento de escravos e ex-escravos, serviu como asilo para menores e crianças de rua, foi confundida com hospício ou casa para abrigar doentes mentais e, finalmente fortaleza para encerrar os inimigos políticos. Monumento máximo de construção da exclusão social, cercado por muros altíssimos ou isolados em ilhas e lugares inóspitos, escondia uma realidade desconhecida, e às vezes aceita pela população: os maus-tratos, a tortura, a promiscuidade e os vícios, uma representação nada agradável do universo carcerário.

Por outro lado, a prisão, vista sob a ótica de aparelho reformador dos indivíduos, recebeu atenção preferencial dos juristas preocupados em edificar modelos perfeitos para o bom gerenciamento da sociedade. São esses modelos, registrados sob a forma de leis, decretos e códigos, que nos possibilitam resgatar as utopias penitenciárias de cada período da história brasileira, e verificar como foram estruturadas as práticas de dominação, na medida em que se estabeleceram relações de força, poder e violência, presentes no tecido social. Sob essa ótica, o sistema penitenciário deve ser observado sob seu aspecto de instituição estruturada com base no poder de punição do Estado e reveladora do aparato de exclusão social.

Nesse sentido, pretendemos nas próximas páginas relatar algumas tentativas para a viabilização do sistema penitenciário brasileiro, calcado em modelos e projetos que se tornaram irrealizáveis em confronto com a realidade carcerária.

\section{A prisão no Brasil: os primeiros passos}

A primeira menção à prisão no Brasil foi dada no Livro V das Ordenações Filipinas do Reino, Có- digo de leis portuguesas que foi implantado no Brasil durante o período Colonial. O Código decretava a Colônia como presídio de degredados ${ }^{1}$. A pena era aplicada aos alcoviteiros, culpados de ferimentos por arma de fogo, duelo, entrada violenta ou tentativa de entrada em casa alheia, resistência a ordens judiciais, falsificação de documentos, contrabando de pedras e metais preciosos (ORDENAÇÕES FILIPINAS, 1870, p. 91) ${ }^{2}$.

A utilização do território colonial como local de cumprimento das penas se estende até 1808 , ano marcado por mudanças significativas rumo à autonomia legal e aos anseios de modernidade, tão em voga naqueles tempos.

A instalação da primeira prisão brasileira é mencionada na Carta Régia de $1769^{3}$, que manda estabelecer uma Casa de Correção no Rio de Janeiro (SILVA MATTOS, 1885) $)^{4}$.

Segundo os rumos da jurisprudência em todo o mundo, a implantação de um sistema prisional se fazia necessária no Brasil. A assimilação da nova modalidade penal se fez pela constituição de 1824 que estipulou as prisões adaptadas ao trabalho e se-

1. Laura de Mello e Souza afirma que a prática do degredo foi um mecanismo pelo qual os portugueses purgaram seus pecados na Colônia. Segunda a historiadora, a mentalidade de época havia estabelecido o Brasil como região onde os pecadores deveriam pagar suas dívidas. MELLO E SOUZA, Laura. O Diabo e a Terra de Santa Cruz. São Paulo, Companhia das Letras, 1986.

2. Ordenações Filipinas. Livro V, títulos XXXII, XXXV, XLII, XLV, XLIX, LII, LVI. Rio de Janeiro, Typographia do Instituto Philomathico, $14^{\mathrm{a}}$ edição, 1870 , p. 91 e segs.

3. As chamadas Casas de Câmara e Cadeia representavam a administração e a Justiça no Brasil durante o período Colonial, servindo essas casas para a reclusão dos condenados, mas não tinham o intuito teórico que passam a ter a partir do século XIX. A reclusão punitiva é a finalidade das primeiras celas no Brasil.

4. SILVA MATTOS, J. da. Reforma Penitenciária: passado e presente. s.e. 1885 
paração dos réus, pelo Código Criminal de 1830 que regularizou a pena de trabalho e da prisão simples, e pelo Ato Adicional de 12 de agosto de 1834, de importância fundamental, que deu às Assembléias Legislativas provinciais o direito sobre a construção de casas de prisão, trabalho, correção e seus respectivos regimes.

A opinião pública também tomou parte nos debates sobre a implantação do regime penitenciário em nosso país. Uma acalorada discussão se fez em torno das formas como esse regime deveria ser adotado. Missões especiais foram enviadas a países como Estados Unidos, Inglaterra e França, com o objetivo de verificar as verdadeiras circunstâncias de aprisionamento e gerenciamento das chamadas prisões-modelo ${ }^{5}$.

A Constituição de 1824 estabelecia que as prisões deveriam ser seguras, limpas, arejadas, havendo a separação dos réus conforme a natureza de seus crimes (CONSTITUIÇÃO DO IMPÉRIO DO BRASIL, ARTIGO 179) ${ }^{6}$, mas as casas de recolhimento de presos do início do século XIX mostravam condições deprimentes para o cumprimento da pena por

5. Vários autores, dentre eles, Souza Bandeira em A Questão Penitenciária no Brasil (Rio de Janeiro, Oliveira, 1881), João Chaves em Sciencia Penitenciária (Lisboa, Classica editora 1912), Esmeraldino Bandeira em "O Criminoso e a Penitenciária" IN Revista da Faculdade Livre de Direito da Cidade do Rio de Janeiro (Rio de Janeiro, volume V, 1909), escrevem detalhadamente suas observações sobre os vários modelos prisionais existentes no mundo.

6. Constituição do Império do Brasil. título VIII, artigo 179, número XX. Rio de Janeiro, Alves \& Cia, s.d. 1 volume.

7. O termo Aljube designava a casa onde se prendiam os Clérigos. O edifício foi construído por subscrição dos eclesiásticos com a colaboração do Estado. No início eram casas dos frades do Carmo, passando a abrigar, após 1748, presos religiosos e, posteriormente, escravos e cristãos novos sujeitos aos casos da Inquisição. parte do detento. Um exemplo deste quadro era a Prisão Eclesiástica do Aljube ${ }^{7}$, localizada na cidade do Rio de Janeiro e instituída pelo Bispo Antonio de Guadalupe após 1735. Com a vinda da Família Real, esta área de reclusão foi transformada em prisão comum, recebendo, posteriormente, o nome de Cadeia da Relação (1823), enquanto que a cadeia passou a abrigar a Câmara dos Deputados. Somente em 1856 é que a Cadeia da Relação foi desativada transformando-se em casa residencial.

Os vários testemunhos sobre a tão famigerada Prisão do Aljube ou da Relação dão-nos o quadro do sofrimento dos presos, apontando para uma história que ainda precisa ser escrita. José Vieira Fazenda, em artigo memorável publicado na Revista do Instituto Histórico e Geographico Brasileiro, cita o relatório da comissão nomeada para visitar as prisões em 1828 que apontou para o aspecto maltrapilho e subnutrido dos presos. Além disso o edifício projetado para abrigar 15 pessoas, comportava, naquela data, cerca de 390 pessoas (FAZENDA, 1921, p. 426) .

Essa casa de reclusão, como tantas outras nos primeiros anos do século XIX, abrigava categorias de presos cujos crimes eram diversos; havia ali paisanos e militares, indivíduos processados por delitos comuns, presos por qualquer motivo ou por nenhum motivo declarado.

O cotidiano carcerário desta prisão revela, além do descaso público, lugar-comum em relação às prisões, aspectos subumanos que apontam para a precária cidadania ou sub-cidadania dos condenados sociais. Mesmo assim, teoricamente, buscava-se o modelo de enclausuramento perfeito.

A prisão, a partir de uma visão utópica, tinha como principais metas:

8. FAZENDA, José Vieira. "Antiqualhas e Memórias do Rio de Janeiro". Revista do Instituto Histórico e Geographico Brasileiro. Rio de Janeiro, Imprensa Nacional, 1921, p. 426. 
- modificar a índole dos detidos através da recuperação dos prisioneiros;

- reduzir o crime, a pobreza e a insanidade social;

- dirigir suas finalidades para a cura e prevenção do crime;

- reforçar a segurança e a glória do Estado (Rothman, 1991, p.30) .

Apesar destes objetivos tão claros, os órgãos públicos pouco se interessavam pela administração penitenciária, que ficava entregue ao bel-prazer dos carcereiros que, por sua vez, instituíam penalidades aos indivíduos privados de liberdade. Assim, a implantação dessas casas foi mascarada por um realidade brutal, possível de ser observada só pelas pessoas que lá conviviam diariamente. Utopias carcerárias pensadas pelos juristas de época entravam em colisão com os poderes presentes na realidade penitenciária.

Por sua vez, o Código Criminal do Império admitiu duas espécies de penas: a prisão simples e a prisão com trabalho, variando a duração de ambas conforme a penalidade aplicada, desde a prisão perpétua até a reclusão de alguns dias. Mesmo com a insistência nesse modelo penitenciário, o artigo 49 do Código Criminal estabelecia que, enquanto não houvesse condições para o cumprimento da pena de prisão com trabalho, ela deveria ser substituída pela pena de prisão simples, com acréscimo da sexta parte do tempo da penalidade prevista. Essa modalidade se defrontou com dificuldades para sua implantação, já que na maioria dos cárceres, as características humildes dos edifícios não comportavam a aplicação de tal sistema inovador: eram casas alugadas e sem acomodações próprias, principalmente as do interior, o que dificultava a instalação de oficinas de trabalho para os presos.

9. ROTHMAN, David. The discovery of the asylum. Boston, Little Brown, 1991, p. 30.
Todo o arcabouço legislativo montado pela regulamentação das prisões e pelo conjunto de leis, decretos e códigos não humanizou o sistema penitenciário; muito pelo contrário, a quantidade de novos mandamentos sobre a conduta e direção das casas de aprisionamento fez com que se perdesse a finalidade da origem da prisão, transformando a instituição em um mero aparelho burocrático. Constatamos, dessa forma, que o mau gerenciamento foi uma das causas que, desde a implantação dos cárceres em território brasileiro, impediu que o objetivo de transformar o condenado em uma "nova pessoa" fosse atingido, retornando, assim, após o cumprimento da pena, à readaptação social.

\section{O ideal republicano}

O Código Penal de 1890 estabeleceu novas modalidades de penas: prisão celular, banimento, reclusão, prisão com trabalho obrigatório, prisão disciplinar, interdição, suspeito e perda do emprego público e multa. $\mathrm{O}$ artigo 44 do Código considerava que não haveria penas perpétuas e coletivas. As penas restritivas de liberdade individual eram temporárias e não deveriam exceder trinta anos. Eram elas: Prisão celular, Reclusão, Prisão com trabalho obrigatório e Prisão disciplinar.

A prisão celular, menina dos olhos dos juristas na época e grande novidade da revisão penal de 1890 foi considerada punição moderna. Foi sob essa modalidade penal que se construiu a abóbada de todo o sistema repressivo brasileiro (MORAES, 1923, p.49) ${ }^{10}$.

Os artigos 50 e 51 do Código Penal de 1890 regulamentavam algumas práticas para a execução da

10. MORAES, Evaristo de. Prisões e instituições penitenciárias no Brasil. Rio de Janeiro, Editora Cons. Cand. de Oliveira, 1923 , p.49. 
pena: o condenado à prisão celular por tempo excedente a seis anos que houvesse cumprido metade da pena, mostrando bom comportamento, poderia ser transferido para alguma penitenciária agrícola, a fim de cumprir o restante da sentença. $\mathrm{O}$ condenado a esta mesma pena incorria em ser interditado nos seguintes itens: suspensão de todos os direitos políticos, perda do emprego e perda de todas as dignidades e condecorações.

A estrutura penitenciária ideal a partir deste novo código passou a exigir os seguintes quesitos:

- segurança dos detentos;

- higiene apropriada ao recinto da prisão;

- segurança por parte dos vigilantes e guardas;

- execução do regime carcerário aplicado;

- inspeções frequientes às prisões.

A questão penitenciária tratava, do ponto de vista ideal, mais do que nunca, das funções que a pena deveria exercer na vida social. Toda essa boa vontade entrou em colisão com as condições deprimentes dos presídios brasileiros, detectáveis através de estudos e depoimentos de época.

Os problemas referentes à execução das penas foram previstos nas disposições gerais do Código ao estabelecer que, enquanto não entrasse em inteira execução o sistema penitenciário, a pena de prisão celular, como a de prisão com trabalho, seriam cumpridas nos estabelecimentos penitenciários existentes, segundo o regime atual; nos lugares onde elas não existissem seria convertida em prisão simples, com aumento da sexta parte do tempo, exceto o tempo em que o condenado passasse trabalhando em estradas públicas, pois esse tempo deveria ser considerado como passado na penitenciária, não estando, portanto, sujeito ao aumento da sexta parte.

\section{O regime carcerário provisório prosseguia.}

A persistência na implantação do regime de trabalho dificultava a sentença proferida para a execu- ção da pena, já que a desorganização, a falta de produtividade, a ausência de matérias-primas e de utensílios para o labor interno nas oficinas da prisão eram uma constante. O detento tornou-se desocupado, promíscuo e preguiçoso. Nesse sentido, de que valia o aparato carcerário, se a meta de recuperar o preso estava sendo realizada erroneamente?

Os críticos desse sistema eram muitos. Dentre eles, destacamos Antonio Bezerra, que em 1900 publicou um projeto de reforma do Código Penal, cujo conteúdo era específico sobre a reforma do trabalho penal. Na opinião de Bezerra a escolha do ofício, pelo preso, conferia um caráter alheio que a ciência penitenciária considerava como trabalho penal. Ao seu ver era um erro nomear a "prisão com trabalho" de "pena restritiva de liberdade", mero formalismo (BEZERRA, 1900, p. 135) ${ }^{11}$.

Além disso, o trabalho do preso deveria ter, dentre outras finalidades, não somente sua futura recuperação, mas também ganhos salariais, dependendo da classe a que pertencesse o preso. A sugestão era de que seu salário fosse dividido em três partes: a primeira recolhida ao tesouro contribuindo para o custeio das despesas da penitenciária; a segunda seria utilizada em proveito do condenado durante o tempo de sua prisão ou de sua família; e a terceira, entregue aos liberados, pela comissão do patronato. Sugestões essas que foram colocadas em prática em 1910 (DECRETO No 8233 DE 22 DE DEZEMBRO DE 1910$)^{12}$.

Tínhamos, assim, uma regulamentação quanto à forma de pagamento pelo trabalho realizado pelo preso, sem estar especificado o tipo de trabalho, a

11. BEZERRA, Antonio. "O projecto de reforma do Código Penal". Revista de Jurisprudência. Rio de Janeiro, 1900, volume 9, p. 135.

12. Decreto ${ }^{\circ} 8233$ de 22 de dezembro de 1910. Coleção de Leis do Brasil. Rio de Janeiro, Imprensa Nacional, 1915, p. 550. 
quantidade de horas dedicadas ao ofício, a insalubridade, se houvesse, entre outros fatores.

Em meio às reformas carcerárias do período, o governo autorizou em 1893 a fundação da Colônia Correcional da Fazenda Bôa Vista, na Paraíba, considerado como local ideal: uma fazenda. Esta colônia foi edificada sob uma antiga colônia militar e deveria receber os indivíduos de qualquer sexo que estivessem vagando pela cidade, em ociosidade; ou os que andassem armados, incutindo o terror ${ }^{13}$.

Os criminosos sociais, os vadios, vagabundos e capoeiras, tinham, assim, legislação e espaço específico muito bem elaborado para a punição nas chamadas colônias correcionais, criadas especialmente com a finalidade de circunscrever a marginalidade das cidades. Outras colônias seguiram o modelo original. Foi o caso da Colônia Correcional de Dois Rios, criada em 1908, com a finalidade de manter as classes perigosas distantes do convívio social. Lá seriam depositados os "ociosos", "imorais" e "reincidentes". Além disso, a Colônia de Dois Rios, quando da sua implantação, foi acompanhada da tentativa de implantação de um núcleo de trabalhadores pobres das cidades que habitariam o espaço rural da colônia e que, para isso, receberiam passagem gratuita, abrigo, e consentimento de moradia, além de trabalho por um prazo máximo de um ano. Com essa medida tentava-se, ao máximo, limpar as cidades através da reclusão social, tanto dos criminosos, como da população carente. Essa medidas visavam uma estratégia repressiva "avançada" na legislação, na medida em que, aliavam a perseguição de criminosos, mas também de pobres e despossuídos, potencialmente considerados perigosos.

Com o passar do tempo, a Colônia de Dois Rios passou a receber qualquer tipo de infrator. A colônia

13. O primeiro projeto de regulamento para as colônias agrícolas data de 1888, estabelecendo o local da instalação, o tipo de regime e os regulamentos gerais para seu funcionamento. recebia pessoas indiscriminadamente: brasileiros ou estrangeiros, sem passagem pela polícia, cuja única finalidade era a residência na colônia, pois se encontravam desempregados e sem recurso na cidade.

As idéias e princípios originais confrontaram-se com a mendicância crescente principalmente na cidade do Rio de Janeiro. As colonnias para os criminosos, não passavam de simples depósitos de indivíduos renegados pela sociedade, principalmente de negros e mulatos, rejeitados pelo contexto econômico-social e dirigidos à reclusão em cárceres ou asilos. O Asilo dos Alienados de São João de Deus, fundado em Salvador em 1874, para os loucos, foi um exemplo concreto dessa prática. $\mathrm{O}$ asilo registrou um contingente de maioria mestiça e negra: ao todo eram 96 "alienados" encarcerados, sendo que 36 eram negros e 31 mulatos e pardos, enquanto que o número de brancos representava a minoria, eram 29 (CARNEIRO, 1993, p. 149) ${ }^{14}$.

No imaginário jurídico a prisão ou colônia correcional deveria causar temor, para que a sociedade se sentisse amedrontada frente ao poder policial ou judicial. A ocultação do condenado nas prisões deveria introduzir no imaginário popular a sensação de que todos eram potencialmente condenáveis e sujeitos ao suplício carcerário. Era a alma o alvo preferencial da punição.

\section{Modernidade e continuidade}

No início do século XX a legitimidade social da prisão ganhou variações para um melhor controle da população carcerária. Surgiram tipos modernos de prisões adequadas à qualificação do preso segundo categorias criminais: contraventores, menores, processados, loucos e mulheres.

14. CARNEIRO, Maria Luiza Tucci. "Negros, loucos negros". Revista USP, $\mathrm{n}^{\circ} 18,1993$, p. 149. 
Os asilos de contraventores, tinham por finalidade o encarceramento dos ébrios, vagabundos, mendigos, em suma, os anti-sociais.

Os asilos de menores se propunham a empregar uma pedagogia corretiva à delinqüência infantil. Pressupondo a inocência do réu, foi proposto uma prisão de processados, considerando-se não conveniente misturá-los com delinqüentes já condenados ou provavelmente criminosos.

Os manicômios criminais foram idealizados para aqueles que sofriam alienação mental e requeriam um regime ou tratamento clínico enquanto que os cárceres de mulheres, seriam organizados de acordo com as indicações especiais determinadas por seu sexo.

Percebemos, nesta forma de distribuição, uma tentativa de racionalização do espaço, adequando-o à tipologia do crime tendo por critério o grau de infração e periculosidade do réu. Com relação às legislações anteriores, houve uma modificação positiva, significativa sobre o fato de se pensar um espaço apropriado para mulheres e menores. A separação do réu, levando-se em conta o sexo e a idade também deve ser observado pelo seu lado técnico. Ao isolar em lugar específico categorias específicas de presos, forma-se um saber mais aprimorado sobre os indivíduos e o controle sobre seus corpos torna-se mais direto e elaborado.

Esse novo mecanismo, por outro lado, tinha por objetivo reforçar a ordem pública, protegendo a sociedade através de uma profilaxia apropriada: o isolamento em um espaço específico.

A utopia prisional passou a ceder algum direitobenefício a certos presos, que se defrontaram com as invenções do surcis e da condicional, que davam liberdade ao preso de "bom comportamento", ou seja àquele que tivesse cumprido parte da pena.

No entanto, o princípio do isolamento dos detidos por categorias criminais entrou em choque com o cotidiano da realidade carcerária, o que impossi- bilitava, em parte, a aplicação dessas modalidades. Por exemplo, na Colonia Correcional de Dois Rios, as mulheres condenadas eram atendidas por um homem; dormiam em edifício separado, mas quando se ocupavam em lavar a roupa, tinham de atravessar os lugares destinados aos presos de sexo masculino, com grande prejuízo para a "ordem" e "moralidade" do presídio (RELATÓRIO DO CONSELHO PENITENCIÁRIO, 1927) ${ }^{15}$.

Outro fator a ser considerado quanto à separação do réu na prisão, era o fato de que deveria levar-se em conta a índole, antecedentes e grau de criminalidade do condenado. A preocupação com a índole do indivíduo revela a preocupação com o caráter, inclinação, tendência, temperamento e propensão ao crime, estipulado através do pré-julgamento da personalidade do preso através da análise de sua fisionomia ${ }^{16}$.

Medidas paliativas também eram tomadas pela direção dos presídios, que viam na punição e no castigo aos presos, formas de suprir as deficiências operacionais dos presídios que, na prática, não ofereciam condições adequadas para a recuperação do delinqüente. Na tentativa de "administrar" a degeneração de alguns e a sublevação de outros, João Pires Farinha, diretor da Casa de Correção do Distrito Federal (RJ), mandou construir em 1907 três celas fortes para nelas serem recolhidos os senten-

15. "Relatório do Conselho Penitenciário do Districto Federal (1924-1946)". Pandectas Brasileiras. Rio de Janeiro, 1927, volume $2,1^{\mathrm{a}}$ parte, p. 84.

16. Julio Caro Baroja em Historia de la fisiognomica. El rosto y el carater.(Madrid, Ediciones Istmo, 1988), historiciza as origens e o desenvolvimento da interpretação do caráter humano a partir do estudo do rosto. Baroja destaca o médico francês Louvergne (1796-1859) - o primeiro a realizar um estudo acerca do físico dos delinquentes encarcerados. 
ciados classificados por ele de "incorrigíveis". $\mathrm{Na}$ sua opinião, estes deveriam ser isolados visto que alguns eram "verdadeiros degenerados, que absolutamente não se corrigem com os castigos impostos pelo regulamento, achando-se ainda em construção mais oito" (RELATÓRIO DA CASA DE CORREÇÃO DO DISTRICTO FEDERAL, 1908) ${ }^{17}$.

Entendemos que a profilaxia se fazia, portanto, em dois estágios: primeiramente apelava-se para os castigos que, no caso de insatisfatórios, conduziam ao isolamento. Medida de grande relevância para o bem da disciplina, uma vez que a punição e o castigo são modalidades de fácil aplicação no universo da detenção.

Lemos Brito em Os sistemas penitenciários do Brasil, registrou em 1924 a situação em que se encontravam as prisões de algumas capitais brasileiras, apontando-a como "nefasta" e "odiosa". A administração carcerária, com base em suas denúncias, chegou a receber uma série de propostas de reformas sugeridas por vários juristas. O próprio Lemos Brito propôs, em 1925, a adoção de um novo sistema penal. As premissas para tais mudanças tinham como ponto de debate a capacidade das prisões e as condições dos cofres públicos.

Com base nessas idéias, a solução para a condição de detenção das mulheres concentrou-se na proposta de se construir uma prisão nacional, localizada no Rio de Janeiro. Ali seriam recolhidas as mulheres criminosas de todos os estados, condenadas a penas maiores de quatro anos mediante a subvenção de cada estado de origem. Com base nos relatórios penitenciários sabemos que a porcentagem de mulheres no cárcere era muito pequena, em torno de 3\%

17. Relatório da Casa de Correção do Districto Federal referente ao anno de 1907. Ministério da Justiça e Negócios Interiores (MJNI), 1908, p.2.

18. LEMOS BRITO, J. G. "Reforma penitenciária no Brasil". Revista de Direito Penal. Rio de Janeiro, s,e., 1933, p. 8. se comparadas aos homens. As causas mais comuns apontadas para a condenação feminina eram: a desordem, vadiagem, furto, ferimentos e infanticídio (LEMOS BRITO, 1933, p. 8) ${ }^{18}$.

A criminalidade não era considerada como um problema insolúvel. Poderia ser resolvido através da prevenção. Nesse sentido, foi decretada em 1924, durante o governo Arthur Bernardes, a criação da Escola de Reforma do Direito Penal, destinada a recolher os menores desprovidos de qualquer orientação de vida: menores reincidentes considerados "rebeldes pelos próprios pais".

Esse universo de idéias acolherá a possível solução do problema penitenciário brasileiro, que pleiteava a criação de reformatórios agrícolas visto que a maioria dos delinqüentes provinham da região rural. O modelo de prisão apresentado custava menos que o industrial e sanearia as grandes cidades das populações marginais que vinham de fora.

A confrontação entre cidade e campo reforçava, na mentalidade de época, os anseios de progresso e modernização. De um lado temos o mundo rural, identificado como a barbárie e atraso; e do outro, a metrópole, como espaço do "novo" atrelado à idéia de progresso. Tais idéias reformadoras, estabeleciam a "modernização" como meta histórica, acobertando a prática da violência e do descaso pelo homem. A concepção de cidade pressupunha trabalho, dinamismo e arraigamento a ela. Logo, os preguiçosos, os não-trabalhadores e estrangeiros não pertenciam ao quadro de legalidade dos habitantes das cidades. A partir da construção dos ilegalismos, moldaram-se os significantes de exclusão, que foram interpretados como "anomalias". Aos desiguais a prisão serviria como "válvula de escape". Limpar fazia parte da construção da disciplina e identidade urbana.

A prisão rural como modalidade de profilaxia ao crime não comportava nenhum tipo de inovação, visto que as colônias agrícolas e correcionais desti- 
nadas aos menores e vadios já existiam. Nessas colônias o cotidiano era de fugas freqüentes, maus tratos do pessoal administrativo, desvio de víveres dos presos, escassez dos meios de comunicação etc. Mesmo assim, os modelos penitenciários das décadas de 20 e 30 buscaram nas colônias agrícolas ou em prisões distantes dos centros urbanos, os locais, por excelência, para o ocultamento da marginalidade à solta nas cidades.

\section{Colônias de Defesa Social}

As medidas de profilaxia ao criminoso social ganharam por parte dos governos dos anos 20 , ações diretas e incursões constantes junto aos possíveis delinqüentes. O constante estado de sítio em vigor naqueles tempos permitiu que a polícia praticasse ações de caráter violento.

Essa nova incursão no meio social, fez com que o governo restabelecesse a Colônia Correcional da Ilha dos Porcos ( na Ilha Anchieta, SP), sob a denominação de Colônia Correcional do Estado de São Paulo, tendo a função de abrigar os reclusos condenados à prisão com trabalho.

As prisões agrícolas foram locais destinados ao ocultamento da delinqüência das grandes cidades. Tal qual a Colônia de Dois Rios ou Clevelândia (no Pará), penitenciárias localizadas fora dos perímetros urbanos nas décadas de 10 e 20 deste século, o Estado apropriou-se dessa modalidade prisional, para nos anos 30 restabelecer novos locais de reclusão, agora com a designação de Penitenciárias Agrícolas.

Em meio a esses modelos utópicos penitenciários, a legislação também ditou regras impraticáveis. O Regimento das correições - corpo de leis que pretendia organizar a rotina dos presos, estabeleceu novas regras: o Corregedor daria audiência aos detentos internos que tivessem queixas e reclamações a fazer; poderia ser solta toda pessoa detida ilegalmente mediante "habeas-corpus"; e ainda seria proibido qualquer tratamento ilegal a que alguém estivesse sujeito.

Uma reforma mais ampla rumo à regulamentação geral das prisões estava em andamento desde 1930. O Código Penitenciário, nas palavras de Lemos Brito, construiria os alicerces relativos aos estabelecimentos penais, regime penitenciário, serviços prisionais, deveres dos funcionários e reclusos. Porém, enquanto a reforma não se concretizava, algumas medidas foram tomadas tentando-se minimizar a situação decepcionante dos cárceres. Na Bahia, por exemplo, o Presídio do Engenho da Conceição sofreu transformações nas condições materiais e internas da prisão, recebendo um novo pavilhão com 120 celas além de acomodamento para os guardas.

Tendo em vista uma organização mais aprimorada do sistema penitenciário, foi aprovado em 1935 o Código Penitenciário da República que, em seus inúmeros artigos, legislava em direção ao ordenamento de todas as circunstâncias que envolviam a vida do indivíduo condenado pela justiça.

As penas detentivas propostas a partir de 1935 seguiam o mesmo pressuposto do Código Penal de 1890: a regeneração do condenado. A preocupação com a situação carcerária interferiu na criação de sanatórios penais, para os quais seriam enviados os presos com sintomas de tuberculose pulmonar. Contaria também com uma seção especial para delinqüentes leprosos, anexada às colônias de leprosos ou em circunscrições penitenciárias; assim como um sanatório de toxicômanos, para o aprisionamento de alcoólatras e viciados em geral.

A organização disciplinar mostrava-se extremamente rígida, sendo que o chefe da Seção disciplinar deveria aplicar as punições pelo Código Penitenciário da República de 1935, censurar as correspondências e observar a devida vigilância aos presos. $\mathrm{O}$ rol de penalidades internas apresentava uma diversidade bem maior que o dos vários regimentos internos dos presídios e do Código de 1890. O Código 
Penitenciário continha sanções extremamente cruéis ao preso, como por exemplo a privação de aulas e a perda do direito de encaminhamento de petições à justiça. Procurava-se por quaisquer meios, a extrema disciplina e obediência do detento com o intuito de puni-lo e não de regenerá-lo.

Foram acionados como modelos ideais de prisão o chamado Sistema de Defesa da Sociedade, composto dos seguintes tipos de prisão:

1. Colônias de Relegação: espécie de instituições para a repressão. Deveriam ser localizadas em ilha ou local distante onde seriam alojados os detentos de péssimos procedimentos provenientes dos reformatórios ou penitenciárias;

2. Casas de Detenção: nestas seriam alojados os processados que aguardavam sentenças e os condenados que esperavam transferência ou vaga em algum presídio;

3. Escolas de Educação Correcional: destinadas aos menores delinquientes de mais de 18 anos e menores de 21 anos e que deveriam proporcionar aos reclusos algum tipo de trabalho;

4. Reformatórios para homens e mulheres delinqüentes: destinados aos reclusos condenados a mais de 5 anos de prisão;

5. Casas de Correção: destinados aos delinqüentes reincidentes e aos considerados difíceis ou irreformáveis, cujo convívio poderia ser prejudicial aos demais reclusos;

6. Colônias para delinqüentes perigosos: destinados aos reincidentes que fossem trabalhar na agricultura;

7. Sanatórios penais: para tuberculosos, leprosos e toxicômanos/alcoólatras.

Este universo de defesa da sociedade, tornou-se viável a partir de circunscrições penitenciárias regionalizadas, havendo prisões na sede de cada município e "pequenas prisões em localidades afasta-

19. Código Penitenciário da República, artigo 241, p. 44. das da mesma sede, desde que quando houvesse autoridade judiciária e policial", e "estabelecimentos centraes na capital do Brasil" (CÓDIGO PENITENCIÁRIO DA REPÚBLICA, 1935) ${ }^{19}$.

Porém, em 1937 - dois anos após a aprovação do novo código - as colônias agrícolas tiveram, por parte do governo um novo tratamento: ali seriam internados apenas os julgados e condenados pelo Tribunal de Segurança Nacional. Segundo a Comissão de Constituição e Justiça, a criação de colônias agrícolas era: " uma necessidade de maior alcance para o problema de regeneração social de criminosos, como também um meio adequado de separar da sociedade elementos que se revelem nocivos á ordem política e social"(DEODORO DE MENDONÇA, 1937,P.16) ${ }^{20}$.

Assim, os criminosos políticos transformados pelo discurso político em "perigo social", deveriam ser encaminhados à reclusão comum, pois poderiam corromper ideologicamente a sociedade. Segundo o sistema, quaisquer divergências à normas do Estado deveriam ser consideradas crime, sendo os comunistas símbolo desse desvio.

Cabe ressaltar que essa prática era realizada anteriormente, mas com finalidades diferentes. Até 1935 o Estado não tinha o interesse em estabelecer diferenças entre preso comum e preso político. Após a Insurreição Comunista as finalidades tornaram-se evidentes: confrontar os dois segmentos da criminalidade, confinando-os num mesmo recinto, visto que para o Estado o preso político não deveria ter qualquer tipo de regalia. Desta forma os presídios destinados a abrigar os detidos políticos passaram a ser

20. Parecer de Deputado Deodoro de Mendonça sobre a mensagem presidencial solicitando a criação de tribunal especial para julgamento de crimes políticos e de colônias penais agrícolas. Câmara dos Deputados, Comissão de Constituição e Justiça 1935-1937. Rio de Janeiro, 1937, p. 16. 
utilizados comumente sob a alegação de falta de vagas nas prisões superlotadas.

Para as Casas de Detenção a legislação reafirmava as anteriores. $\mathrm{O}$ estabelecimento estava destinado aos reclusos que aguardavam julgamento; aos condenados à pena de detenção e aos condenados que aguardavam transferência. Às Casas de Correção deveriam ser enviados apenas os condenados reincidentes. No entanto, a obrigatoriedade do trabalho penitenciário continuava a ser enfatizada pelo Código, procurando atingir todas as formas de reclusão. Pretendia-se através dessa prática, aliviar os cofres públicos das despesas com a manutenção das prisões, assim como promover a educação profissional do preso e sua readaptação social.

A distribuição e organização desse tipo de trabalho estariam sujeitas às características da prisão: se industrial, agrícola, mista ou de pesca. A remuneração ao trabalho do detento seria feita mensalmente, mediante depósito em uma caderneta e, parte desse pecúlio seria destinada à manutenção da prisão, custeio do preso, despesas ou auxílio à família. Quando de sua libertação, o preso teria acesso ao dinheiro depositado.

O Estado capitalista via no trabalho do preso uma saída com relação aos custos da prisão e como uma pretensa produtividade do recluso: o detento deveria produzir alguma coisa.

\section{A Cidade Prisional}

A busca de soluções trouxa à luz outros tantos projetos irrealizáveis, como por exemplo o da Cidade Penitenciária do Rio de Janeiro que, idealizada em 1937, propunha formas contemporâneas de regeneração ao preso segundo o modelo de uma "prisão moderna". Pretendia-se dar ao prisioneiro condições de uma vida mais saudável no interior do cárcere ou seja: assistência médica, dentista, esporte, educação, trabalho e distração.
Este projeto de Cidade Prisional, segundo o arquiteto Adelardo Caiuby visava uma total segurança contra possíveis fugas ou rebeliões internas, além de prever a detenção de um maior número de presos para futura regeneração (CIDADE PENITENCIÁRIA DO DISTRICTO FEDERAL, 1937) ${ }^{21}$.

Com relação aos menores, previa-se, também, a construção de uma Cidade de Menores no Distrito Federal. A idéia começou a ser pensada em 1936, com a inauguração do Laboratório de Biotipologia Infantil, do juizado de menores, que atenderia a 600 crianças. A capacidade de instalação proposta era para 1000 menores distribuídos em 28 lares internos.

O projeto previa:

1. Escolas e Oficinas com base na regeneração;

2. Estádio para cultura física, construído no centro da cidade;

3. Hospital, biblioteca, capela e lavanderia;

4. Cinema para menores e cassino para os funcionários;

5. Horta, pomar, estábulos para vacas leiteiras;

6. Oficinas de encadernação, tipografia, impressão e máquinas.

Frente ao mega projeto da construção da Cidade Penitenciária do Rio de Janeiro, a idéia da penitenciária modelo foi colocada em questão, porque o ambiente e a conduta que o preso deveria seguir em estabelecimento deste tipo não condizia com a situação de sua vida extra-muros. A realidade do preso deveria ser levada em conta: “... precisamos não de um hotel para sentenciados, como lá se denomina o estabelecimento moderno, de cellulas hygienicas e regime salutar, onde os párias se acostumem a uma vida de conforto e tratamento, que jamais haviam tido e que dificilmente po-

21. Cidade Penitenciária do Districto Federal. MJNI, Imprensa Nacional, 1937.

22. TORRES, Margarino. “Penitenciária Modelo!'Revista do Direito Penal. Rio de Janeiro, 1938, volume 20, p. 181. 
derão manter após o cumprimento da pena..." (TORRES, 1938, p. 191) 22 .

O ideal reformador defrontou-se com as reais condições das prisões. No interior do país o problema chegou a ser desesperador. Problema esse que se arrastou ainda por muito tempo, e, que nem o Código Penal de 1940 conseguiu corrigir na prática: “...dada a insuficiência das prisões municipais onde se acumulam, entre paredes e grades, homens de todas as condições sociais, e até menores, mulheres e loucos. E o que mais chocante é, muitas delas de fachadas modernizadas, por exigências de urbanismo, mas cujo interior vale por um escárnio e por um contraste desalentador do que se mostra fora ." (LEMOS BRITO, 1942, p.442) ${ }^{23}$.

Projetos mirabolantes como esses terminaram esquecidos frente à necessidade de vagas em vários presídios brasileiros.

\section{Selo Penitenciário}

A situação constrangedora, que ia desde a depravação, falta de higiene, de conforto e de ordem nos infectos e superlotados presídios onde se confundiam e se misturavam menores de todas as idades e criminosos de todos os graus, era uma verdade.

Com o objetivo de minimizar esta somatória de problemas do cárcere foi proposta a circulação de um selo penitenciário, aprovado pelo Presidente da República em julho de 1934. A criação do selo visava a solução desta agravante situação das prisões em todo o país, especialmente, na capital da República, cuja situação era alarmante. Candido Mendes de Almeida, presidente do Conselho Penitenciário, ligado ao Mi-

${ }^{23}$ LEMOS BRITO, J. G. "Da prisão preventiva e do regime que se deve adotar nos estabelecimentos destinados a indiciados". Anais do $1^{\circ}$ Congresso Nacional do Ministério Público. São Paulo, 1942, vol. 7, p. 442. nistério da Justiça e Negócios Interiores, defendia a necessidade de tal investimento ao criticar a execução da pena criminal que, ao ser ver, era quase: "ilusória por causa da insufficiência e da inaptidão dos estabelecimentos penaes" (CRIAÇÃO DE UM FUNDO PENITENCIÁRIO DESTINADO À REALIZAÇÃO DE REFORMAS PENAES, 1934) ${ }^{24}$.

Segundo Candido Mendes a lei criaria um selo especial - o selo penitenciário - cuja arrecadação seria destinada à celebração das reformas penais no Brasil. Para isso a verba arrecadada ficaria à disposição do ministro da justiça que a aplicaria:

- na construção, reformas e manutenção dos estabelecimentos penitenciários, colônias de egressos e penitenciários;

- no cadastro judiciário;

- no auxílio aos patronatos e aos asilos destinados a filhos de condenados;

- na Administração Geral Penitenciária;

- na realização de outras providências convenientes à prevenção e à repressão criminal.

Além disso, esta verba destinar-se-ia, também, a financiar a representação do Brasil em congressos internacionais penitenciários assim como para preparar juristas para o exercício perfeito de sua vocação.

A lei previa também os dispositivos necessários à sua aplicação. Os projetos e orçamentos deveriam ser organizados por uma Inspectoria Geral Penitenciária composta por pessoas consagradas à especialidade da matéria. Esta seria constituída pelo Conselho Penitenciário do Distrito Federal, dependendo da aprovação do Ministério da Justiça. Caberia a fisscalização do dinheiro público a um titular da pasta da Justiça.

Aprovada em 1937, a Inspetoria Geral Penitenciária deveria colocar em prática as providências convenientes à prevenção e reeducação do preso além

24. Criação de um fundo penitenciário destinado à realização de reformas penaes. MJNI, parecer de 19.07.1934. 
de gerenciar a Administração Geral Penitenciária, organizar projetos e instalar novos presídios, colônias de egressos e auxiliar aos patronatos, protegendo os liberados. O campo de trabalho da Inspetoria deveria abarcar o complexo mundo do cárcere ou seja, desde as coisas mais práticas, sem perder o objeto de seu trabalho: o preso.

O selo seria impresso pela Casa da moeda e vendido pelo Tesouro Federal na Capital e nos Estados. Estavam obrigados a utilizar o selo todos aqueles que realizassem as seguintes operações:

1. pagamento de multas relativas a infrações penais de qualquer natureza;

2. para todas as sentenças condenatórias nos processos penais;

3. dez por cento sobre o movimento diário de todos os estabelecimentos onde haja apostas de dinheiro ou de jogo;

4. Dois por cento sobre a receita global de futebol e box, ou qualquer competição atlética ou esportiva;

5. renda produzida pelas certidões do cadastro penitenciário, entre outros.

Em decorrência da dificuldade de arrecadação do novo imposto, Candido Mendes de Almeida, em despacho ao ministro da justiça Vicente Ráo, solicitou que fosse facilitada a sua cobrança, e que se recomendasse que as autoridades policiais exigissem dos cassinos, clubes, empresas, jockeis e outros, a exibição diária da quitação do pagamento desse selo. Assim sendo, nova forma de controle social foi acionada: "As autoridades policiaes poderão prohibir funcionamento desses estabelecimentos sempre que lhes fôr recusada a exhibição dessas quitações relativas á receita a véspera ou do dia immediatamente

25. Ofício no 2164 de 5 de dezembro de 1936. Regulamento da inspectoria Geral Penitenciária. Conselho Penitenciário do Districto Federal. anterior (OFÍCIO No 2164 DE 5 DE DEZEMBRO DE 1936) ${ }^{25}$.

Entretanto, a questão social ultrapassava o espaço das prisões. Outros segmentos da sociedade clamavam por ajuda, como por exemplo o menor abandonado e o delinqüente. Outra finalidade para a arrecadação do selo foi dada por Mendes de Almeida: empregar o dinheiro na construção de instituições para crianças abandonadas. A justificativa para tal investimento na infância foi o temor de que, no futuro, esses menores abandonados fossem os candidatos em potencial para as prisões. Cuidando-se assim da criança desamparada estar-se-ia cortando o mal pela raiz (CARTA DE CANDIDO MENDES DE ALMEIDA PARA VICENTE RÁO, 1937) ${ }^{26}$.

Em 1939 foi apresentado um novo projeto sobre o selo penitenciário com pequenas diferenças se comparadas com a proposta aprovada em 1934. A principal dizia respeito ao pagamento do selo que, no seu artigo $4^{\circ}$, estipulava que dois por cento deveria ser arrecadado sobre a quota da loteria. Os demais dispositivos eram destinados a tornar eficiente a arrecadação, bem como equiparar os dispositivos do selo penitenciário aos do selo comum (PARECER SOBRE O PROJETO DE REGULAMENTO DA INSPETORIA GERAL PENITENCIÁRIA, 1939) ${ }^{27}$.

Se aprovado o selo, colocaria em prática a estimativa de arrecadação de um novo imposto em seiscentos contos de réis para os primeiros anos de vigoração no mercado.

\section{Soluções alternativas}

26. Carta de Candido Mendes de Almeida para Vicente Ráo, sobre a construção de estabelecimentos penitenciários destinados à preservação de menores abandonados e delinquentes. Rio de Janeiro, 29.03.37.

27. Parecer sobre o projeto de Regulamento da Inspetoria Geral Penitenciária. MJNI, 1939. 
A necessidade de mais vagas nas prisões e a criação de um abrigo para mulheres criminosas era uma discussão que se fazia presente há décadas. Em despacho datado de 1932 o presidente do Conselho Penitenciário do Distrito Federal, Candido Mendes de Almeida, solicitou ao Ministro da Educação e Saúde Pública, Francisco Antunes Maciel Junior, que cedesse a fazenda Santa Maria em Jacarepaguá anteriormente destinada à instalação de uma Penitenciária Agrícola para mulheres delinqüentes.

A situação das mulheres criminosas na capital federal era, segundo o presidente do Conselho Penitenciário, miserável. A título de comparação Mendes de Almeida retoma como padrão as penitenciárias femininas dos "países civilizados", cujas presas teriam qualidades. No Brasil os esforços não atingem as transformações almejadas: "A mais miseranda e, por isso, desde 1922 o Patronato das presas vem empregando os mais intensos esforços para conseguir um estabelecimento penal especializado, a exemplo do que se pratica em todos os paízes civilisados e principalmente na América do Norte, onde as nossas patricias têm revelado qualidades carcerárias emeritas" (DESPACHO DO PRESIDENTE DO CONSELHO PENITENCIÁRIO, 1935) ${ }^{28}$.

Essa situação persistiu até 1934, quando iniciouse uma acirrada discussão sobre a concessão da fazenda Santa Rita onde se pretendia a instalação da Penitenciária Agrícola para mulheres e do Lazareto da Ilha Grande com o objetivo de descongestionar as Casas de Detenção e Correção do Rio de Janeiro. A Diretoria de Saúde Pública receberia, em troca, uma parte da Ilha Bom Jesus para a instalação de um porto sanitário marítimo na Bahia da Guanabara. Com relação à fazenda Santa Rita, um pequeno tre-

28. Despacho do Presidente do Conselho Penitenciário. MJNI, 13.12.1935 cho desta se destinaria à construção de um posto sanitário para tuberculosos.

Em 24 de março de 1934, durante a reunião do Conselho Penitenciário, houve entrave em torno do assunto. Lemos Brito, integrante do Conselho, assinalou que desde o início do governo provisório, elaborara um projeto de colônia agrícola penal de regeneração, a instalar-se em terras da união. Que tal projeto fora aprovado, com ligeiras alterações pelo Conselho, devendo ser encaminhado a Oswaldo Aranha, Ministro da Justiça. No entanto, alegava não saber que destino havia sido dado a esse trabalho.

O debate transcorreu em torno da utilização do Lazareto que teve seus defensores. Dentre eles estavam Candido Mendes, e seus oponentes, como Lemos Brito, que insistia que qualquer obra de emergência, falharia aos objetivos. Outro componente do Conselho, Heitor Carrilho, por sua vez, achava que a idéia do Lazareto não resolveria o problema: ao contrário, prejudicaria a realização das medidas radicais e gerais que, de longa data, vinha o conselho reclamando (ATA DA REUNIÃO DO CONSELHO PENITENCIÁRIO, 1934) ${ }^{29}$.

Por fim a votação foi proposta por Roberto Lyra sendo rejeitada a realização de qualquer obra de emergência. Recomendava-se também ao governo o início da execução do plano contido no ante-projeto do Código Penitenciário, preferindo-se a construção de pavilhões para leprosos, tubeculosos e mulheres em local definitivo.

Em 1935 a discussão foi novamente retomada, ficando agora o Ministério da Justiça interessado na Ilha do Annanaz, fronteira à Ilha das Flores (RJ), para ali ser igualmente criado um núcleo de reclusão carcerária. O Departamento Nacional de Povoamento já havia, no entanto, declarado que a Ilha das Flores,

29. Ata da reunião do Conselho Penitenciário. MJNI, 24.03.1934 
onde estava instalada a Hospedaria de Imigrantes e cuja área não excedia de quatro hectares, não possuía água nascente e que o abastecimento era apenas suficiente para o consumo regular do pessoal existente no local. Em troca da Ilha do Annanaz, o Ministério da Educação receberia um edifício de vastas dimensões localizado no centro urbano (SOBRE A CESSÃO DA FAZENDA SANTA RITA, 1934) ${ }^{30}$.

A utilização do Lazareto de Dois Rios e das enfermarias de imigrantes da Ilha das Flores, para escoar a superpopulação das penitenciárias, foi substituída por uma nova proposta de Floriano Rei, diretor da Casa de Detenção do Rio de Janeiro, que seria a de remover os presos para o manicômio judiciário, sob a alegação destes serem criminosos psicopatas: "A permanência desses presidiários, bem como a de alguns outros contumazes em rebeldia e faltas disciplinares, constitue grave perigo à segurança da prisão. A sua remoção para o manicômio judiciário seria a primeira solução, (...) pois que aquele que atentar contra a própria vida (greve de fome), e perturbar a ordem (disciplinar) e que não se submeter ao tratamento que o caso aconselhar (os recalcitrantes), devem ser recolhidos ao manicômio judiciário, bem como, é proibido manter-se psicopatas em cadeias públicas ou entre criminosos, e é positivamente um psicopata que se acomete contra si mesmo" (CARTA DE FLORIANO REI AO MINISTRO DA JUSTIÇA, 1933) ${ }^{31}$.

Pretendia-se dessa forma internar os indisciplinados e rebeldes no Manicômio Judiciário, como se estes fossem loucos, apesar da constatação de Mendes de Almeida, que considerava o manicômio como "local lamentável, de extrema exigüidade, e que para

30. Sobre a cessão da Fazenda santa Rita e do Lazareto da Ilha Grande. MJNI, 1934

31. Carta de Foriano Rei ao Ministro da Justiça. MJNI, 13.12.1933. tão importantes serviços deveria ser mais amplo e melhor localizado" (COMUNICADO AO MINISTRO DA JUSTIÇA ANTUNES MACIEL, 1934) ${ }^{32}$.

Uma outra solução foi dada pelo mesmo diretor à prisão de sete detentos, condenados por assalto a mão armada. Foram colocados em cubículos contendo cal, após uma greve de fome deflagrada pelos presos (CARTA DE FLORIANO REI AO MINISTRO DA JUSTIÇA, 1933) $)^{33}$.

Outra estratégia, agora largamente utilizada para o aprisionamento, foi a utilização dos navios para o alojamento dos presos, como foi o caso do Navio $D$. Pedro I, que ficava ancorado defronte às docas, no Rio de Janeiro. Este navio foi símbolo da violência do governo Getúlio Vargas, pois sua finalidade era aprisionar os revoltosos e oposicionistas durante a década de 30.

\section{Geopolítica das Prisões}

A utilização de navios, colônias correcionais, prisões comuns ou ilhas para o confinamento carcerário fez parte das estratégias em torno de uma geopolítica das prisões, implantadas a partir da criação das colônias correcionais. O intuito era de afastar o criminoso dos grandes centros urbanos, objetivando o saneamento da sociedade: mais uma forma de profilaxia social.

Percebemos durante a década de 30 a identificação das autoridades com tais idéias colocadas em prática nos governos anteriores. A utilização de na-

32. Comunicado de 25 de maio de 1934 ao Ministro da Justiça Francisco Antunes Maciel. O Presidente do Conselho Penitenciário comunica ter visitado o Manicômio Judiciário. MJNI, 1934.33. Carta de Floriano Rei ao Ministro da Justiça. MJNI, 22.04.1933.

33. Carta de Floriano Rei ao Ministro da Justiça. MJNI, 22.04.1933. 
vios-presídios e de ilhas como locais de confinamento e a acomodação de mulheres prisioneiras nos mesmos recintos onde ficavam reclusos os homens, apenas vem comprovar que a penitenciária designava-se à punição, pura e simplesmente. Cabe averiguarmos hoje, se houve mudanças e se elas fora efetivas ou, se não ocorreram, o que isso evidencia.

A prática da tortura no universo carcerário corroborou, ainda mais, para ampliar a dimensão política da prisão. A geopolítica do confinamento desvenda as artimanhas da eliminação do inimigo nocivo ao Estado brasileiro. A construção do mundo da reclusão durante os séculos XIX e XX significou não só a limpeza das ruas contra o inimigo aparente - o vagabundo -, mas, um artimanha para encerrar todos os inimigos, quer fossem eles de vertentes ideológicas, como os comunistas, ou sociais, representados pelos bandidos comuns. Punir e castigar essa gama de desclassificados significou a atribuição do

\section{Bibliografia}

ARAÚJO, Cesário. A hygiene das prisões, precedida de considerações gerais a cerca da reforma penitenciária. Rio de Janeiro, Typographia do Diario de N. L. Vianna, 1844.

ASUA, Luis Jiménez. Un Viaje al Brasil. Madrid, Editorial Rei, 1929. BARRETO, Paulo. Alma Encantadora das ruas. s.e., 1908.

BARROS, Alfredo de. Notas e apontamentos sobre minha prisão na fortaleza da Conceição, na correção... desde 4 de novembro de 1893 até 14 de agosto de 1894. Rio de Janeiro, Jornal do Brasil, 1895.

BASTOS, José Tavares. Penitenciaria para mulheres criminosas: applicação desta these entre nós precedida do estudo da mulher ante o direito penal. São Paulo, Duprat, 1915.

CAMPELO, Barreto. Colonizaçao penal da selva brasileira: these de concurso a professor cathedrático de direito penal da Faculdade do Recife. Rio de Janeiro, Editora ABC, s.d.

CARNEIRO, Augusto Accioly. Os penitenciários, a alma do condenado, o regime celular. Rio de Janeiro, H. Velho, 1930. poder de vida e morte ao Estado, que se utilizou desses atos para promover uma "nova ordem social", concretizada durante os governos das décadas de 20 e 30 deste século.

Fundamental é frisar, no final deste texto, que a inoperância das instituições públicas brasileiras funcionou em prol da mentalidade autoritária de época, e trabalhou na criação de lugares excludentes do mundo civilizado; sempre tomando como base modelos ideais e perfeitos de aprisionamento - as utopias penitenciárias -, sobre as quais, os juristas, via de regra, acreditavam que proporcionando leis em favor desses pressupostos, livrariam os bons homens dos perigos que circulavam visivelmente pelas ruas das cidades; protegiam o Estado do perigo que o afrontava e, sobretudo, levariam à regeneração social o futuro encarcerado. Mera utopia. Na atualidade presenciamos os frutos colhidos dos delírios dessa classe jurídica-penitenciarista.

CHAVES, João. Sciencia Penitenciaria. Lisboa, Classica editora, 1912 .

DRUMMOND, José de Magalhães. Aspectos do problema penal brasileiro. Rio de janeiro, Sfredo \& Gravina, s.d.

EXPILLY, Charles. Le Brésil tel qu'il est. Paris-Leipsig, JungTreuttel éditeur, 1862.

FIGUEIREDO, José Rodrigues. Systema Penitenciario na província da Bahia. Salvador, Typographia Poggetti de Tourinho \& Cia, 1864.

INGENIEROS, José. Sistema penitenciario. Buenos Aires, Penitenciaria Nacional, 1911.

ISSA ÁSSALY, Alfredo. O Trabalho penitenciário: aspectos econômicos e sociais. São Paulo, Livraria Martins Editora, 1944.

LEAL, Aureliano. Regimen penitenciario na Bahia. Rio de Janeiro, Imprensa Nacional, 1924.

LEMOS BRITO, J. G. Os Systemas penitenciarios do Brasil. Rio de Janeiro, Imprensa Nacional, 1924. 
LEMOS BRITO, J. G. Colônias e prisões no Rio da Prata. Bahia, Livraria Catilina, 1919.

LUCAS, Charles. De la réforme des prisons ou de la théorie de l'emprisonnement. Paris, Legrand, 1838.

MORAES, Evaristo de. Prisões e Instituições Penitenciárias no Brazil. Rio de Janeiro, Livraria e editora Conselheiro Candido de Oliveira, 1925.
SILVA MATOS, João da. Reforma penitenciaria, passado e presente. Lisboa, Sousa Neves, 1885.

SOUZA BANDEIRA, S. G. A questão penitenciaria no Brazil. Rio de Janeiro, Oliveira, 1881.

VIANA, Paulo Domingues. Regimen penitenciario segundo as preleções do Dr. Lima Drummond. Rio de Janeiro, Jacintho Ribeiro dos Santos, 1914. 